\title{
Combinatorial Polymer Electrospun Matrices Promote Physiologically-Relevant Cardiomyogenic Stem Cell Differentiation
}

\author{
Mukesh K. Gupta ${ }^{1,2}$, Joel M. Walthall ${ }^{2,3}$, Raghav Venkataraman ${ }^{1}$, Spencer W. Crowder ${ }^{1,2}$, Dae Kwang \\ Jung ${ }^{1,2}$, Shann S. Yu ${ }^{1,2}$, Tromondae K. Feaster ${ }^{2,3,4}$, Xintong Wang ${ }^{1,2}$, Todd D. Giorgio ${ }^{1}$, Charles C. \\ Hong $^{2,3,4}$, Franz J. Baudenbacher ${ }^{1}$, Antonis K. Hatzopoulos ${ }^{2,3,4}$, Hak-Joon Sung ${ }^{1,2 *}$
}

1 Department of Biomedical Engineering, Vanderbilt University, Nashville, Tennessee, United States of America, 2 Center for Stem Cell Biology, Vanderbilt University, Nashville, Tennessee, United States of America, 3 Department of Medicine, Division of Cardiovascular Medicine, Vanderbilt University, Nashville, Tennessee, United States of America, 4 Department of Cell and Developmental Biology, Vanderbilt University, Nashville, Tennessee, United States of America

\begin{abstract}
Myocardial infarction results in extensive cardiomyocyte death which can lead to fatal arrhythmias or congestive heart failure. Delivery of stem cells to repopulate damaged cardiac tissue may be an attractive and innovative solution for repairing the damaged heart. Instructive polymer scaffolds with a wide range of properties have been used extensively to direct the differentiation of stem cells. In this study, we have optimized the chemical and mechanical properties of an electrospun polymer mesh for directed differentiation of embryonic stem cells (ESCs) towards a cardiomyogenic lineage. A combinatorial polymer library was prepared by copolymerizing three distinct subunits at varying molar ratios to tune the physicochemical properties of the resulting polymer: hydrophilic polyethylene glycol (PEG), hydrophobic poly $(\varepsilon-$ caprolactone) (PCL), and negatively-charged, carboxylated PCL (CPCL). Murine ESCs were cultured on electrospun polymeric scaffolds and their differentiation to cardiomyocytes was assessed through measurements of viability, intracellular reactive oxygen species (ROS), $\alpha$-myosin heavy chain expression ( $\alpha-\mathrm{MHC}$ ), and intracellular $\mathrm{Ca}^{2+}$ signaling dynamics. Interestingly, ESCs on the most compliant substrate, 4\%PEG-86\%PCL-10\%CPCL, exhibited the highest $\alpha$-MHC expression as well as the most mature $\mathrm{Ca}^{2+}$ signaling dynamics. To investigate the role of scaffold modulus in ESC differentiation, the scaffold fiber density was reduced by altering the electrospinning parameters. The reduced modulus was found to enhance $\alpha$-MHC gene expression, and promote maturation of myocyte $\mathrm{Ca}^{2+}$ handling. These data indicate that ESC-derived cardiomyocyte differentiation and maturation can be promoted by tuning the mechanical and chemical properties of polymer scaffold via copolymerization and electrospinning techniques.
\end{abstract}

Citation: Gupta MK, Walthall JM, Venkataraman R, Crowder SW, Jung DK, et al. (2011) Combinatorial Polymer Electrospun Matrices Promote PhysiologicallyRelevant Cardiomyogenic Stem Cell Differentiation. PLoS ONE 6(12): e28935. doi:10.1371/journal.pone.0028935

Editor: Che John Connon, University of Reading, United Kingdom

Received September 5, 2011; Accepted November 17, 2011; Published December 27, 2011

Copyright: (c) 2011 Gupta et al. This is an open-access article distributed under the terms of the Creative Commons Attribution License, which permits unrestricted use, distribution, and reproduction in any medium, provided the original author and source are credited.

Funding: VIIBRE, Vanderbilt startup, National Institutes of Health grant HL091465, Vanderbilt Internal Discovery Grant (\#4-48-999-9132). The funders had no role in study design, data collection and analysis, decision to publish, or preparation of the manuscript.

Competing Interests: The authors have declared that no competing interests exist.

*E-mail: hak-joon.sung@vanderbilt.edu

\section{Introduction}

Myocardial infarction (MI) is a leading cause of death in the United States and throughout the Western world. Following MI, massive cardiomyocyte death occurs, eventually leading to the development of arrhythmias and/or congestive heart failure [1]. Myocardium is terminally differentiated tissue with limited regenerative capacity which cannot compensate for the large scale loss of cardiac tissue after MI. Currently, heart transplantation is a viable treatment method for the end stage congestive heart failure, but is not applicable for early stages of disease progression and is restricted by the limited number of donors. Cell-based therapies have therefore emerged as new potential therapeutic options for treating cardiac diseases [2].

Recently, in situ cellular cardiomyoplasty, a technique in which cells are delivered directly onto the hypertrophic myocardium, has shown promise as a potential strategy for myocardial regeneration following MI. Several types of donor cells have been used for this purpose, including fetal [3] and adult [4] cardiomyocytes, skeletal myoblasts [5], bone marrow derived hematopoietic stem cells [68], mesenchymal stem cells [8,9], intrinsic cardiac stem cells [10,11] and embryonic stem cells (ESCs) [12-18]. ESCs offer excellent therapeutic potential in terms of the capacity for selfrenewal and the ability to differentiate into cardiomyocytes in vitro, thereby functionally replacing the diseased cardiac tissue $[13,14,17]$. The clinical translation of this approach, however, is limited by retention, survival and differentiation of ESCs at the injury site. For example, approximately $90 \%$ of cells are lost while circulating the vasculature or simply leak out of the injection site [19]. Additionally, the results from preclinical and clinical studies based on this method have generated inconclusive and mixed results [5,20-22], indicating that the clinical translation of this approach is questionable.

An alternative therapeutic strategy to overcome these limitations is cardiac tissue engineering, a process in which cells are cultured on a natural or synthetic scaffold in vitro before 
implantation at the injury site [23]. For example, we plan to introduce the regenerated cardiac tissues at the site of injury directly attached to the matrix in a patch form. This will give the cells a foundation to adhere and grow and also minimize any inflammatory response. The properties of the scaffold can be manipulated to control cell behavior, including differentiation towards a specific lineage. The material design criteria for this type of application include (i) elasticity similar to that of native myocardium (ii) a biodegradation rate that allows for generation of new tissues, (iii) biocompatible degradation byproducts, (iv) the ability to retain and deliver cells and growth factors, (v) stabilization of cellular interactions with the myocardium, and (vi) the ability to direct differentiation of cells towards a cardiac lineage $[24,25]$. ESC activity can therefore be directed by an instructive scaffold prior to implantation, thereby improving the post-operative therapeutic efficacy.

Geron Corporation (Menlo Park, CA) is currently at the forefront of regenerative medicine using embryonic stem cells for spinal cord injury [26,27] and also has clinical trials in progress for cardiovascular remodeling. However, Geron uses proteins such as bone morphogenetic protein-4 to direct ESC differentiation. We present here the use of a selective small molecule BMP inhibitor, DMH1, based on our previous work that chemical inhibition of BMP is a robust, efficient and scalable means to induce myocardial differentiation in mouse ES cells [28].

The selection of cells and biomaterial plays an important role in tissue regeneration $[29,30]$. Here, we hypothesized that polymeric biomaterial scaffolds with distinct chemical and mechanical properties could be employed to enhance the differentiation of ESCis to cardiomyocytes as a potential patch for cardiac repair. The various types of synthetic materials composed of poly(ethylene glycol), poly(lactic acid), poly(glycolic acid) and their copolymer poly(lactic-co-glycolic acid) have been applied in myocardium tissue engineering, however, the poor elasticity of these materials renders them unsuitable for myocardium patches [31]. In this study, we prepared a library of combinatorial copolymers containing different mole percentages of three components: hydrophilic polyethylene glycol (PEG), hydrophobic poly( $\varepsilon$ caprolactone) (PCL), and negatively-charged carboxylated-PCL (CPCL) to tune the physicochemical, mechanical, and bioactive scaffold properties for the control of ESG differentiation. Each polymer subunit was selected for the specific properties it contributes to the resulting copolymer: PCL is a semi-crystalline, biodegradable, hydrophobic polymer that has been FDAapproved in certain devices [32]; PEG is a non-toxic, biocompatible and hydrophilic polymer that reduces protein adsorption and cell attachment through steric exclusion; and CPCL facilitates cell attachment to the scaffold surface by providing a negative charge, effectively counteracting the repellant PEG effect [33]. These polymers were electrospun to create the extracellular matrix (ECM)-mimetic fiber structure and their effects on cardiac differentiation of ESCs were evaluated through a series of in vitro studies.

In this study, we present the effects of the physicochemical and mechanical scaffold properties on enhanced cardiac differentiation of ESCs through analysis of biochemical activities, gene and protein expression, and physiologically-relevant intracellular calcium signaling dynamics. Significant progress has been made recently in terms of developing a proper biomaterial format (e.g., injectable hydrogel and, stimuli-responsive scaffolds, and three dimensional co-culture system) [34-36] as a potential vehicle of delivering ESCs to dysfunctional myocardium and/or a means of promoting their cardiac differentiation. Our results provide important insight into the structure-function relationships that connect the chemical and mechanical properties of polymeric biomaterials with physiologically-relevant cardiomyogenic differentiation of ESCs using a combinatorial library of ECM-mimetic electrospun fiber scaffolds.

\section{Materials and Methods}

\section{Chemicals, reagents, and polymers}

$\varepsilon$-caprolactone and benzyl alcohol were purchased from Alfa Aesar (Ward Hill, MA, USA). Tin (II) ethyl hexanoate $\left(\mathrm{Sn}(\mathrm{Oct})_{2}\right)$, benzyl alcohol, monomethoxypoly(ethylene glycol) (PEG) $\left(\mathrm{M}_{\mathrm{n}}=5000\right)$, anhydrous tetrahydrofuran $(\mathrm{THF})$, lithium diisopropylamide (LDA) (2M in THF/n-heptane), anhydrous toluene, dichloromethane, diethyl ether were purchased from SigmaAldrich Chemicals (St. Louis, MO, USA); and were used as purchased unless otherwise noted. $\varepsilon$-caprolactone was dried and distilled over $\mathrm{CaH}_{2}$ immediately before polymerization. Tin (II) ethyl hexanoate was distilled under high vacuum. Benzyl alcohol was dried and distilled over $\mathrm{CaH}_{2}$.

Copolymers of $x \mathrm{~mol} \%$ PEG, $y \mathrm{~mol} \%$ PCL, and $z \mathrm{~mol} \%$ CPCL were identified as $x \%$ PEG- $b-y \%$ PCL- $c o-z \%$ CPCL where PEG-PCL is a block copolymer but CPCL addition is random within the PCL subunit. The polymers are abbreviated $x \%$ PEG$y \%$ PCL- $z \%$ CPCL.

\section{Synthesis of poly ( $\varepsilon$-caprolactone) PCL and $\mathrm{x} \% \mathrm{PEG}-\mathrm{y} \% \mathrm{PCL}$ diblock copolymers}

PCL was synthesized through ring-opening polymerization of $\varepsilon$ caprolactone in bulk using benzyl alcohol and $\mathrm{Sn}(\mathrm{Oct})_{2}$ as the initiator and catalyst, respectively [37]. Briefly, CL $\left(100 \times 10^{-3} \mathrm{~mol}, 11.4 \mathrm{~g}, 10.96 \mathrm{~mL}\right), \mathrm{Sn}(\mathrm{Oct})_{2}\left(100 \times 10^{-6} \mathrm{~mol}\right.$, $40 \mathrm{mg})$, and benzyl alcohol $\left(100 \times 10^{-6} \mathrm{~mol}, 0.10 \mathrm{~g}, 0.10 \mathrm{ml}\right)$ were placed in a previously flame dried, $100 \mathrm{~mL}$ round bottom flask equipped with three-way stopcock connected to manifold and degassed for $30 \mathrm{~min}$ with three freeze-pump-thaw cycles. The ampoule was immersed in an oil bath at $140^{\circ} \mathrm{C}$. After 4 hour reaction, polymerization was stopped by cooling and the resulting polymer was dissolved in dichloromethane and precipitated into excess of diethyl ether. The structure was characterized by ${ }^{1} \mathrm{H}$ NMR spectra. ${ }^{1} \mathrm{H}$ NMR $\left(\mathrm{CDCl}_{3}\right)=\delta 4.06\left(\mathrm{t}, 3 \mathrm{H},-\mathrm{OCH}_{2}\right), 2.31(\mathrm{t}$, $\left.2 \mathrm{H},-\mathrm{CH}_{2}\right), 1.66\left(\mathrm{~m}, 2 \mathrm{H},-\mathrm{CH}_{2}\right), 1.37\left(\mathrm{~m}, 4 \mathrm{H},-\mathrm{CH}_{2}\right) \mathrm{ppm}$.

The same method was used to synthesize $\mathrm{x} \% \mathrm{PEG}-b$ - $\mathrm{y} \% \mathrm{PCL}$ diblock copolymers, except with a stoichiometric amount of $5 \mathrm{kDa}$ monomethoxy-PEG in place of benzyl alcohol as the initiator (Figure 1). Polymer structure was characterized by ${ }^{1} \mathrm{H}$ NMR spectra. 4\%PEG-96\%PCL: ${ }^{1} \mathrm{H}$ NMR $\left(\mathrm{CDCl}_{3}\right)=\delta 4.06(\mathrm{t}, 3 \mathrm{H}$, $\left.-\mathrm{OCH}_{2}\right), 3.65\left(\mathrm{~s}, 4 \mathrm{H},-\mathrm{OCH}_{2}\right), 2.31\left(\mathrm{t}, 2 \mathrm{H},-\mathrm{CH}_{2}\right), 1.66(\mathrm{~m}, 2 \mathrm{H}$, $\left.-\mathrm{CH}_{2}\right), 1.37\left(\mathrm{~m}, 4 \mathrm{H},-\mathrm{CH}_{2}\right)$ ppm. 8\% PEG-92\%PCL: ${ }^{1} \mathrm{H}$ NMR $\left(\mathrm{CDCl}_{3}\right)=\delta 4.06\left(\mathrm{t}, 3 \mathrm{H},-\mathrm{OCH}_{2}\right), 3.65\left(\mathrm{~s}, 4 \mathrm{H},-\mathrm{OCH}_{2}\right), 2.31(\mathrm{t}, 2 \mathrm{H}$, $\left.-\mathrm{CH}_{2}\right), 1.66\left(\mathrm{~m}, 2 \mathrm{H},-\mathrm{CH}_{2}\right), 1.37\left(\mathrm{~m}, 4 \mathrm{H},-\mathrm{CH}_{2}\right) \mathrm{ppm}$.

\section{Synthesis of $90 \% \mathrm{PCL}-10 \% \mathrm{CPCL}$ copolymer and x\%PEG-y\%PCL-z\%CPCL terpolymers}

Carboxylated PCL (CPCL) was synthesized as previously reported [37]. PCL $(8.0 \mathrm{~g}, 0.067 \mathrm{~mol})$ in $400 \mathrm{~mL}$ of anhydrous THF was added under dry nitrogen to a previously flame-dried round bottom flask. The stirred solution was placed in dry ice/ acetone bath and degassed with three pump-thaw cycles. A solution of LDA, $2 \mathrm{M}$ in THF/ $n$-heptane $(33.5 \mathrm{~mL}, 0.067 \mathrm{~mol}$ : 1 equivalent per monomeric unit), was added drop wise with a syringe into the reaction, which was then stirred for 30 minutes at $-78^{\circ} \mathrm{C}$ in a bath of dry ice and acetone. A stream of dry $\mathrm{CO}_{2}$ gas was then generated by addition of concentrated $\mathrm{H}_{2} \mathrm{SO}_{4}$ to dry $\mathrm{Na}_{2} \mathrm{CO}_{3}$, and allowed to bubble through the solution for 
<smiles>COCCOC</smiles>

PEG $\left(M_{n}=5000\right)$

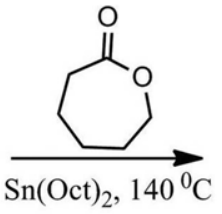

meot OOt $_{\mathrm{x}}^{\mathrm{H}}$

x\%PEG-b-y\%PCL

i) LDA, THF, $-78^{\circ} \mathrm{C}$

ii) $\mathrm{CO}_{2}$

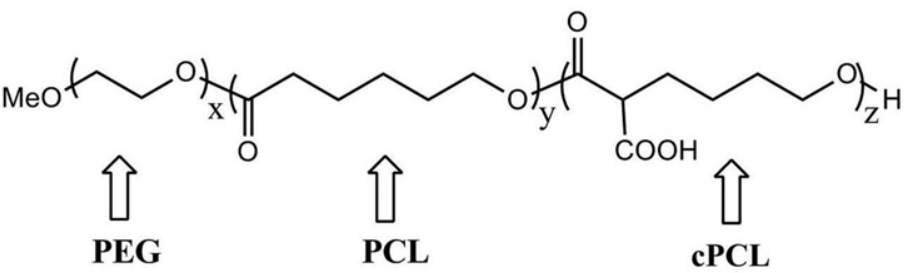

x\%PEG-b-y\%PCL-co-z\%cPCL

Figure 1. Schematic representation of polymer synthesis PEG-PCL block copolymers were first synthesized by ring-opening polymerization. $\mathrm{CPCL}$ was then randomly added within the $\mathrm{PCL}$ subunit. Polymers are abbreviated $x \% \mathrm{PEG}-\mathrm{y} \% \mathrm{PCL}-z \% C P C L$. doi:10.1371/journal.pone.0028935.g001

30 minutes. An aqueous solution of $\mathrm{NH}_{4} \mathrm{Cl}$ was added to the flask to quench the reaction mixture. The resulting solution was acidified with an aqueous solution of concentrated $\mathrm{HCl}$ to $\mathrm{pH} 2-$ 3. The resulting copolymer was extracted twice with $100 \mathrm{~mL}$ of dichloromethane. The combined organic phases were washed twice with $20 \mathrm{~mL}$ of distilled water and dried over anhydrous $\mathrm{Na}_{2} \mathrm{SO}_{4}$. After filtration, the solvent was partly evaporated under reduced pressure and the polymer was precipitated from the resulting, concentrated solution by addition of diethyl ether. The 90\% PCL-10\%CPCL copolymer was dried under vacuum for $24 \mathrm{~h}$ and stored at $-20^{\circ} \mathrm{C}$ prior to use. ${ }^{1} \mathrm{H}$ NMR $\left(\mathrm{CDCl}_{3}\right)=\delta 4.06(\mathrm{t}$, $\left.3 \mathrm{H},-\mathrm{OCH}_{2}\right), 3.4(\mathrm{~m}, 1 \mathrm{H},-\mathrm{CH}-\mathrm{COOH}), 2.31\left(\mathrm{t}, 2 \mathrm{H},-\mathrm{CH}_{2}\right), 1.66$ $\left(\mathrm{m}, 2 \mathrm{H},-\mathrm{CH}_{2}\right), 1.37\left(\mathrm{~m}, 2 \mathrm{H},-\mathrm{CH}_{2}\right) \mathrm{ppm}$.

To synthesize $\mathrm{x} \%$ PEG- $b$-y $\%$ PCL- $c o$-z $\%$ CPCL terpolymers, the same protocol was applied, except using 4\%PEG-96\%PCL and 8\% PEG-92\% PCL in place of PCL as starting materials (Figure 1). $4 \%$ PEG-86\%PGL-10\% CPCL: ${ }^{1} \mathrm{H}$ NMR $\left(\mathrm{CDCl}_{3}\right)=\delta 4.06(\mathrm{t}, 3 \mathrm{H}$, $\left.-\mathrm{OCH}_{2}\right), 3.4(\mathrm{~m}, 1 \mathrm{H},-\mathrm{CH}-\mathrm{COOH}), 2.31\left(\mathrm{t}, 2 \mathrm{H},-\mathrm{CH}_{2}\right), 1.66(\mathrm{~m}$, $\left.2 \mathrm{H},-\mathrm{CH}_{2}\right), 1.37\left(\mathrm{~m}, 2 \mathrm{H},-\mathrm{CH}_{2}\right)$ ppm. 8\% PEG-82\% PCL10\%CPCL: ${ }^{1} \mathrm{H}$ NMR $\left(\mathrm{CDCl}_{3}\right)=\delta 4.06\left(\mathrm{t}, 3 \mathrm{H},-\mathrm{OCH}_{2}\right), 3.4(\mathrm{~m}$, $1 \mathrm{H},-\mathrm{CH}-\mathrm{COOH}), 2.31\left(\mathrm{t}, 2 \mathrm{H},-\mathrm{CH}_{2}\right), 1.66\left(\mathrm{~m}, 2 \mathrm{H},-\mathrm{CH}_{2}\right), 1.37$ $\left(\mathrm{m}, 2 \mathrm{H},-\mathrm{CH}_{2}\right) \mathrm{ppm}$.

\section{Characterization of polymer synthesis}

Gel permeation chromatography (GPG) was performed on a Tosoh Biosciences TSKGel SuperHZ-M mixed bed column $\left(4 \times 10^{6} \mathrm{Da}\right.$ exclusion limit; THF mobile phase $)$ incubated at $40^{\circ} \mathrm{C}$, with a Shimadzu SPD-10A UV detector and RID-10A refractive index detector (Shimadzu Scientific Instruments, Columbia, MD, USA), and a Wyatt miniDAWN Treos multiangle light scattering detector (MALS; Wyatt Technology, Santa Barbara, CA, USA). Molecular weight $\left(\mathbf{M}_{\mathrm{n}}\right)$ and polydispersities $\left(\mathrm{M}_{\mathrm{w}} / \mathrm{M}_{\mathrm{n}}\right)$ were determined against monodisperse poly(methyl methacrylate) standards (PMMA; Varian Inc., Palo Alto, CA,
USA). ${ }^{1} \mathrm{H}$ NMR spectra were recorded on a Brüker $400 \mathrm{MHz}$ spectrometer with $\mathrm{CDCl}_{3}$ as solvent.

\section{Electrospinning and Scanning Electron Microscopy (SEM)}

For electrospinning, polymer solutions $(10 \mathrm{wt} \%)$ in a mixture of chloroform and methanol ( $4: 1$ by volume) was loaded into a plastic syringe $(10 \mathrm{ml})$ fitted with a stainless steel needle. This needle was connected to a high-voltage power supply. The solution was continuously supplied using a syringe pump at a rate of $1 \mathrm{ml} /$ hour for 10 minutes (e.g. high fiber density meshes). The voltage used for electrospinning was $18 \mathrm{kV}$ and the collection distance was $10 \mathrm{~cm}$. The resulting fibers were collected over glass cover slips placed on a rotating mandrel at $1200 \mathrm{rpm}$. The scaffolds were dried under vacuum for 24 hours and sterilized by UV irradiation for 30 minutes before cell culture. This procedure has been proven to remove toxic organic solvents and sterilize polymer substrates effectively in previous studies [33,38,39].

To reduce the modulus of electrospun fibers (e.g. low fiber density meshes), the flow rate of polymer solution was reduced from 1 to $0.25 \mathrm{ml} /$ hour while keeping the other conditions same. The fibers were collected over an aluminum woven wire mesh with a wire diameter of $1.0 \mathrm{~mm}$, a wire spacing of $0.381 \mathrm{~mm}$, and a dimension of $25 \mathrm{~mm}(L) \times 10 \mathrm{~mm}(W)$ (McMaster-Carr Co., Robbinsville NJ, USA).

For SEM imaging, electrospun scaffolds were coated with gold using a sputter coater (Cressington Scientific, Watford, United Kingdom) and their fiber structures were examined using SEM (Hitachi S-4200, Tokyo, Japan) at an accelerating voltage of $5 \mathrm{kV}$.

\section{Mechanical testing}

Dry elastic moduli of electrospun polymer scaffolds were determined using a tabletop uniaxial testing machine (Bose ElectroForce 3100, Eden Prairie, MN, USA) using a 10-N load cell under a cross-head speed of $10 \mathrm{~mm} / \mathrm{min}$ in ambient 
conditions $(\mathrm{n}=3-6)$. Scaffold samples were prepared in a uniform rectangular form. The thicknesses of test specimens were $0.1 \mathrm{~mm}$ as measured using digital calipers.

Wet elastic moduli of electrospun polymer scaffolds were measured by dynamic mechanical analysis (DMA, Q800 DMA, TA Instruments, New Castle, DE, USA) $(n=3)$. Scaffold samples were prepared in a uniform rectangular form with the dimension of $15.0(\mathrm{l}) \times 6.6(\mathrm{w}) \mathrm{mm}^{2}$. A wet stress and strain curve was obtained using a submersion clamp containing water at room temperature. A preload force of $0.1 \mathrm{~N}$ was applied to each sample and force was increased at a rate of $0.1 \mathrm{~N} / \mathrm{min}$ until failure.

\section{ESC culture}

For cell assays, mouse germ line competent CGR8 embryonic stem cells (European Collection of Cell Cultures, Salisbury, United Kingdom) were used. To monitor cardiomyogenic differentiation, CGR8 cells were stably transfected with a construct expressing the red fluorescent protein gene fused to a nuclear localization signal (DsRed-Nuc) under the $\alpha$-myosin heavy chain $(\alpha-M H C)$ promoter. Therefore, $\alpha$-MHC-expressing cells are marked with red nuclear fluorescence, allowing a visual, quantitative assessment of differentiating cardiomyocytes [40]. CGR8 ESCs were cultured in GMEM medium with 10\% fetal bovine serum (FBS), 100 units/ $\mathrm{ml} \mathrm{LIF,} 2 \mathrm{mM}$ L-glutamine and $50 \mu \mathrm{M} \beta$-mercaptoethanol. ESCs were grown in differentiation medium (IMDM containing 20\% FBS, $0.1 \mathrm{mM}$ MEM essential amino acids, $2 \mathrm{mM}$-glutamine and $100 \mu \mathrm{M} \beta$ - mercaptoethanol), and maintained in $37^{\circ} \mathrm{C}$ under $5 \%$ $\mathrm{CO}_{2}$ before use.

Embryoid bodies (EBs) were formed at day 0 by inverting droplets consisting of $2.5 \times 10^{4} \mathrm{ESCs} / \mathrm{ml}$ in media without LIF in the presence of Noggin (300 ng/mL) [41] until day 4. Lyophilized Noggin was purchased from R\&D Systems (MN, USA), reconstituted with $1 \times$ Phosphate-Buffered Saline (PBS) containing $0.1 \% \mathrm{BSA}$ as $10 \mathrm{mg} / \mathrm{ml}$ stock solutions. To confirm our findings, cardiomyogenesis was alternatively induced in EBs by administration of a selective small molecule inhibitor of BMP type-1 receptor, $\mathrm{DMH} 1$ (final concentration, $0.5 \mu \mathrm{M}$ ), during day 0 to 2 of differentiation [28]. Previously, we showed that a small molecule BMP inhibitor could replace Noggin in the above mentioned ESC-cardiac induction protocol [28].

After 2 days, the EBs were transferred from hanging drop culture into Petri dishes. For high fiber density substrates, EBs were moved at day 4 to electrospun polymer scaffolds coated with $0.2 \%$ gelatin on glass cover slips in tissue culture plates. For low fiber density substrates, fiber meshes were immobilized to the membrane side of modified transwell insert after removing the insert membrane. The differences in seeding methods result from the inability of low density fibers to remain effectively attached to cover slips; therefore, these meshes were held in place with the modified transwell insert. At day 10, in vitro measurements were performed upon visual confirmation of the presence of beating EBs.

\section{Intracellular Reactive Oxygen Species (ROS) and Cell Viability}

Beating, $\alpha$-MHC-DsRed-transfected CGR8 cells at day 10 were used to measure intracellular ROS production and cell viability. Intracellular hydrogen peroxide production was measured using dichlorofluorescein diacetate (DCFDA, Invitrogen) following established methods [38,42]. Cell viability was measured using calcein AM (Invitrogen). The fluorescence intensity was measured on a Tecan infinite F500 plate reader (Männedorf, Switzerland) and normalized to the corresponding cell number measured from Hoechst nuclear staining.

\section{Gene and protein expression of $\alpha-\mathrm{MHC}$}

To measure $\alpha$-MHC expression, total RNA was extracted from ESCs using the RNeasy Mini Kit (Qiagen, Valencia, CA) according to the manufacturer's instructions and subsequently treated with RNase-free DNase I (Qiagen). Equal concentrations of RNA were then reverse-transcribed using the iScript cDNA synthesis kit (Bio-Rad). Real time-PCR was performed on the BioRad iCycler iQ (Hercules, CA) using the iQ SYBR Green Supermix (Bio-Rad) $(\mathrm{n}=3)$ and the following primers (all purchased from Sigma-Aldrich): GAPDH forward 5'-CTCACTCAAGATTGTCAGCAATG-3' and GAPDH reverse 5'-GAGGGAGATGCTCAGTGTTGG-3'; $\alpha$-MHC forward $5^{\prime}$-TACACTCTTCTCTAGGTATGGTTCT- $3^{\prime}$ and $\alpha$-MHC reverse 5'-CAGTATCTTCTTGAACTCAATGC-3'. Each primer pair was tested and its melt curve was analyzed to ensure that only a single amplicon was generated. Each test sample was assayed for target gene or GAPDH (reference gene) and the average value was used as CT. To perform statistical analyses and for graphical representation, target gene $\mathrm{C}_{\mathrm{T}}$ values $(\mathrm{A})$ and $\mathrm{GAPDH} \mathrm{C}_{\mathrm{T}}$ values (B) were both expressed as exponents of 2 , and data represented as the ratio of $2^{\mathrm{A}} / 2^{\mathrm{B}}$, or $2^{(\mathrm{A}-\mathrm{B})}$.

To measure $\alpha$-MHC protein expression, the red fluorescence intensity of ESCs transfected with the $\alpha$-MHC-DsRed fusion was measured through image analysis $(n=4)$. The fluorescence intensity was normalized to the corresponding cell number measured from Hoechst nucleus staining.

\section{Intracellular Calcium dynamics}

EBs were mechanically detached from their polymer substrates and re-suspended in $2 \mathrm{ml}$ culture media. EBs were then incubated for 15 minutes with $5 \mu \mathrm{M}$ of the cell-permeant $\mathrm{Ca}^{2+}$ sensitive fluorophore Fura-2 AM (Invitrogen). EBs were then resuspended in fresh, dye-free media for 15 minutes to allow for deesterification of the acetoxymethyl ester (AM) dye molecule.

In order to record $\mathrm{Ca}^{2+}$ transients, each $\mathrm{EB}$ was field-stimulated at $1 \mathrm{~Hz}$ in a custom built imaging dish using platinum wire electrodes. Excitation light was multiplexed at wavelengths of $360 \mathrm{~nm}$ and $380 \mathrm{~nm}$ using a computer controlled monochromator (Cairn, UK). Resulting fluorescence was recorded at a wavelength of $510 \pm 20 \mathrm{~nm}$ using an array of optical fibers positioned in the focal plane of a Zeiss Axiovert 200 microscope (Oberkochen, Germany) coupled to photomultiplier tubes (Hamamatsu Photonics, Shizuoka, Japan). Recordings were taken at multiple sites on each EB. Computed fluorescence ratios $\left(\mathrm{I}_{360 \mathrm{~nm}} / \mathrm{I}_{380 \mathrm{~nm}}\right)$ were post-processed with a $200 \mathrm{~Hz}$ low-pass filter. The transient amplitude was defined as the difference between the systolic and diastolic fluorescence ratios. The decay constant was computed by fitting a single exponential decay starting from the maximum fluorescence ratio using Origin (OriginLab, MA, USA).

\section{Immunohistochemistry}

At day 11, EBs were fixed with 2\% paraformaldehyde and permeabilized with $0.2 \%$ Triton X-100. Cells were blocked with $5 \%$ bovine serum albumin in PBS for 30 minutes at $37^{\circ} \mathrm{C}$. Cells were then incubated with Rabbit anti-mouse SERCA2a (Sarcoplasmic Reticulum $\mathrm{Ca}^{2+}$ ATPase isoform 2a) IgG antibody (provided by Dr. Sabine Huke at Vanderbilt University Medical Center) in $1: 1000$ dilution with $5 \%$ bovine serum albumin in PBS for 1.5 hours at $37^{\circ} \mathrm{C}$, followed by incubation with secondary FITC-conjugated goat anti-rabbit IgG antibodies (Sigma-Aldrich). The cells were imaged under a Nikon Eclipse $\mathrm{Ti}$ inverted fluorescence microscope (Nikon Instruments Inc, Melville, NY). 


\section{Statistical Analysis}

In all experiments, results are presented as means \pm standard error mean (SEM). Comparisons between individual sample groups were performed using an unpaired Student's t-test. For all statistics, $\mathrm{p}<0.05$ was considered statistically significant.

\section{Results}

\section{Polymer synthesis and characterization}

The test polymers with the general formula $x \%$ PEG- $y \%$ PCL$z \%$ CPCL were synthesized (Figure 1) $[37,43]$. The carboxyl groups in CPCL were introduced into the PCL chain by anionic activation of the $\alpha$-methylene proton by LDA followed by further reaction with carbon dioxide $\left(\mathrm{CO}_{2}\right)$ [37]. Characterization of the resulting polymers by GPC revealed that the $\mathrm{M}_{n}$ ranged from 65$112.5 \mathrm{kDa}$, relative to monodisperse PMMA standards (Table 1).

Polymers were electrospun over glass cover slips to form fiber networks. The diameter, morphology and alignment of fibers were kept constant by applying similar electrospinning conditions [44]. The average diameter of fibers was found to be $0.5 \mu \mathrm{m}$. Table 1 shows dry and wet elastic moduli of electrospun polymer meshes. The polymers exhibited dry elastic moduli ranging from 7.58 \pm 1.0 to $23.21 \pm 6.38 \mathrm{MPa}$. Among all scaffolds tested, PCL exhibited the lowest dry elastic modulus $(7.58 \pm 1.0 \mathrm{MPa})$, whereas the stiffest material was the 4\%PEG-86\%PCL-10\%CPCL terpolymer $(23.21 \pm 6.38 \mathrm{MPa})$. Following hydration to equilibrium, PEG- and CPCL-containing polymers exhibited a greater decrease in wet elastic modulus compared to PCL. Because CPCL and PEG subunits are hydrophilic, segments containing these moieties became less rigid upon hydration, causing a large decrease in wet elastic modulus.

\section{Maintenance of ESC Viability on Electrospun Fiber Scaffolds and Differentiation to Cardiomyocytes}

To evaluate ESC viability and their differentiation into cardiomyocytes on fiber scaffolds, EBs [28] were induced to differentiate towards cardiomyocytes by Noggin treatment and grown on scaffolds for six days. Upon visual confirmation of contracting cells, cell viability, intracellular ROS levels, $\alpha-\mathrm{MHC}$ expression at the gene and protein levels, and $\mathrm{Ca}^{2+}$ ion dynamics were measured.

EBs on all test polymer types showed higher cell viability compared to control (glass coverslip without polymer, Figure 2a).

Table 1. Characterization of polymer properties.

\begin{tabular}{|c|c|c|c|c|}
\hline Polymer & $\begin{array}{l}M_{n}{ }^{a} \\
(D a)\end{array}$ & PDI & $\begin{array}{l}\text { Dry modulus } \\
\text { (MPa) }\end{array}$ & $\begin{array}{l}\text { Wet } \\
\text { modulus } \\
\text { (MPa) }\end{array}$ \\
\hline PCL & 91,720 & 1.25 & $7.58 \pm 1.0$ & $0.79 \pm 0.18$ \\
\hline 4\%PEG-96\%PCL & 93,070 & 1.24 & $21.29 \pm 3.21$ & $0.81 \pm 0.01$ \\
\hline 8\%PEG-92\%PCL & 104,200 & 1.21 & $15.40 \pm 0.77$ & $0.74 \pm 0.04$ \\
\hline $90 \%$ PCL-10\%CPCL & 112,800 & 1.06 & $13.33 \pm 2.79$ & $0.98 \pm 0.04$ \\
\hline $\begin{array}{l}\text { 4\%PEG-86\%PCL- } \\
10 \% \text { CPCL }\end{array}$ & 108,400 & 1.16 & $18.11 \pm 2.46$ & $0.71 \pm 0.04$ \\
\hline $\begin{array}{l}\text { 8\%PEG-82\%PCL- } \\
10 \% \text { CPCL }\end{array}$ & 65,350 & 1.27 & $23.21 \pm 6.38$ & $0.81 \pm 0.02$ \\
\hline
\end{tabular}

$M_{n}$ was measured by GPC according to $d n / d c$ light scattering values. Wet and dry moduli were calculated from stress/strain measurements.

${ }^{a}$ Molecular weight measured by GPC in THF,

${ }^{\mathrm{b}}$ Measured on a uniaxial Bose ElectroForce 3100 mechanical tester, 'Measured by DMA.

doi:10.1371/journal.pone.0028935.t001
In particular, PCL, 4\%PEG-96\%PCL, 8\%PEG-92\%PCL and 4\%PEG-86\%PCL-10\%CPCL exhibited the most significant enhancement in cell viability. Since intracellular ROS have been implicated in ESG differentiation towards both cardiomyogenic and vascular cell lineages [45-47], we measured intracellular hydrogen peroxide $\left(\mathrm{H}_{2} \mathrm{O}_{2}\right)$ and found that test polymer types differentially regulated intracellular $\mathrm{H}_{2} \mathrm{O}_{2}$ production (Figure $2 \mathrm{~b}$ ). In particular, the terpolymer types (i.e., 4\%PEG-86\%PCL10\% CPCL and 8\% PEG-82\%PCL-10\%CPCL) enhanced intracellular $\mathrm{H}_{2} \mathrm{O}_{2}$ most significantly.

To further quantify the differentiation of ESCs to cardiomyocytes, gene expression of $\alpha$-MHC, a marker of the cardiac lineage, was measured with real time PCR (Figure 2c). EBs on all test polymer types up-regulated $\alpha$-MHC gene expression compared to control. EBs grown on terpolymer fiber scaffolds (i.e., 4\%PEG86\%PCL-10\%CPCL and 8\%PEG-82\%PCL-10\%CPCL) exhibited the greatest increase in $\alpha$-MHC gene expression $(\sim 2$-fold relative to control). To further confirm $\alpha$-MHC expression, transfected EBs on fiber scaffolds were imaged and the overall fluorescence intensity from the $\alpha$-MHC promoter was quantified through image analysis (Figure 3). Representative phase contrast and fluorescence images demonstrate improved attachment of EBs on 4\% PEG-86\%PCL-10\%CPCL relative to control (Figure 3a). EBs on the 4\%PEG-86\%PCL-10\%CPCL scaffolds also exhibited faster beating rates compared to control (data not shown). Interestingly, the level of $\alpha$-MHC-related fluorescence in EBs was dependent on the polymer composition (Figure 3b). EBs cultured on 4\%PEG-96\%PCL and 4\%PEG-86\%PCL-10\%CPCL scaffolds exhibited up-regulated $\alpha$-MHC expression relative to control whereas protein expression was substantially downregulated in the other test polymer groups.

Taken together, 4\%PEG-86\%PCL-10\%CPCL was found to be the most favorable polymer composition for maintaining EB viability and enhancing their differentiation to cardiomyocytes, whereas $100 \%$ PCL was found to be the least favorable composition for the cellular activities tested.

\section{Effects of Scaffold Mechanical Properties on ESC Differentiation}

Mechanical properties of a polymer substrate can be tuned by changing electrospinning parameters [44]. Two groups of fiber scaffolds with different fiber densities were prepared: the first was prepared by spinning at a flow rate of $1 \mathrm{ml} /$ hour for $10 \mathrm{~min}$, and the second was prepared by reducing the flow rate $(0.25 \mathrm{ml} /$ hour $)$ and doubling the deposition time (20 minutes) to reduce fiber density. The orientation could change due to the reduced flow rate of electrospun polymer solution as the less polymer solution flows towards the rotting mandrel [44]. However, the results from assessing the fiber orientation did not show any significance difference between the low and high fiber density groups (data now shown). Due to the resulting scaffold morphology by SEM, these two scaffold types will be referred to as 'high' (Figure 4a) and 'low' (Figure 4b) fiber density scaffolds, respectively.

Scaffold fiber density proportionally correlated with wet elastic modulus (Figure 4c). PCL scaffolds with high and low fiber densities exhibited wet moduli of $0.79 \mathrm{MPa}$ and $0.42 \mathrm{MPa}$, respectively. 4\%PEG-86\%PCL-10\%CPCL scaffolds of high and low fiber densities exhibited lower moduli than PCL (0.71 and $0.28 \mathrm{MPa}$, respectively). This is likely due to the hydrophilicity of PEG and CPCL in 4\%PEG-86\%PCL-10\% CPCL which resulted in increased hydration and water retention relative to hydrophobic PCL. As a consequence, polymer chains within the terpolymer scaffolds were better hydrated and separated more freely in an aqueous environment, leading to lower moduli. 

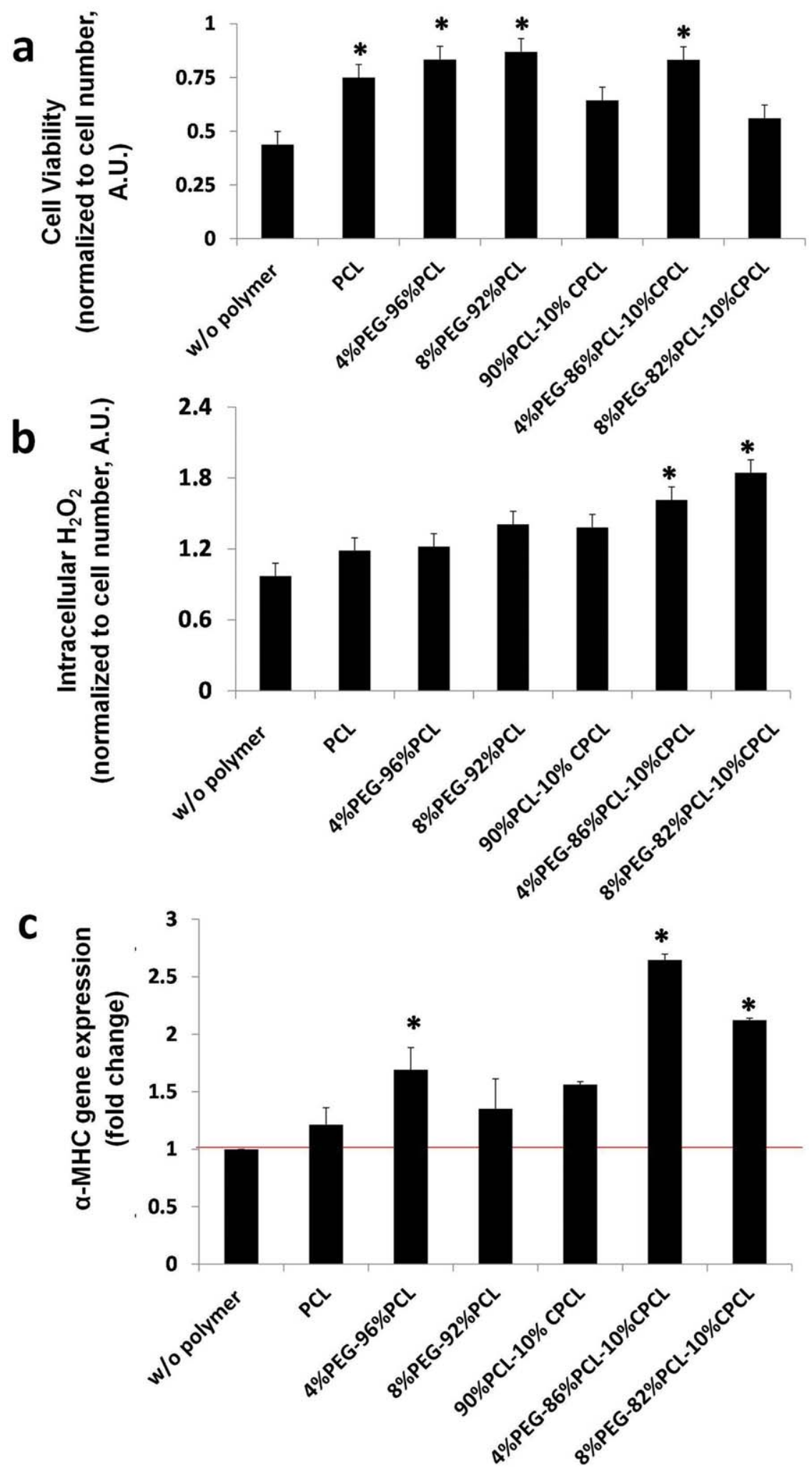

Figure 2. Biochemical activities of EBs on polymer scaffolds. Electrospun polymer scaffolds were shown to enhance cardiac-related biochemical activities of EBs, compared to control. (a) Cell viability, (b) intracellular $\mathrm{H}_{2} \mathrm{O}_{2}$, and (c) $\alpha$-MHC gene expression. ${ }^{*} p<0.05$ versus control. doi:10.1371/journal.pone.0028935.g002

To evaluate the effects of fiber density on EB differentiation at the gene level, EBs were cultured on two polymers types (PCL and 4\%PEG-86\%PCL-10\%CPCL) at low and high fiber densities and
$\alpha$-MHC gene expression was measured. Cardiomyogenic differentiation of EBs was shown to be significantly influenced by scaffold mechanical properties (Figure 4d). For both polymer types 
a
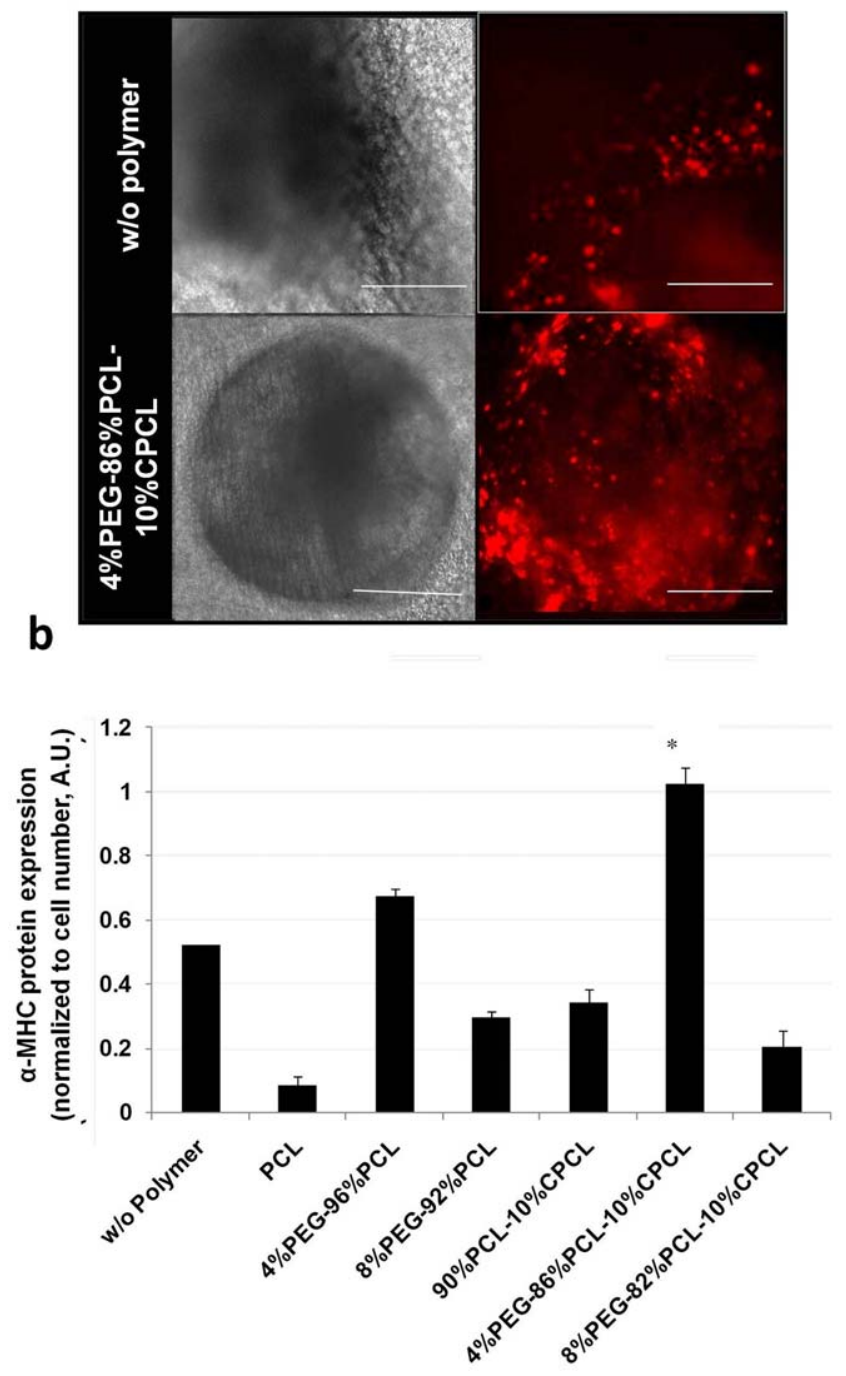

Figure 3. EB attachment and protein expression. (a) Phase contrast and fluorescence images of EBs are shown at day 10. Cells were cultured on gelatin coated glass cover slips with and without 4\%PEG$86 \%$ PCL-10\%CPCL copolymer scaffolds. Cells grown on $4 \%$ PEG$86 \%$ PCL-10\%CPCL maintained more adhered, circular EBs and (b) exhibited higher $\alpha$-MHC protein expression. Scale bars $=10 \mu \mathrm{m}$. * $p<0.0005$ versus control.

doi:10.1371/journal.pone.0028935.g003

tested, low fiber density scaffolds with decreased moduli promoted higher $\alpha$-MHC gene expression than high fiber density scaffolds of the same material (2-fold higher for PCL, 3-4-fold higher for $4 \%$ PEG-86\%PCL-10\%CPCL). These results indicate that more elastic substrates enhance the differentiation of $\mathrm{EBs}$ into cardiomyocytes in the presence of Noggin.

\section{Intracellular Calcium Signaling Dynamics}

$\mathrm{Ca}^{2+}$ handling in cardiomyocytes constitutes a well-defined sequence of events. $\mathrm{Ca}^{2+}$ influx into the cells via the voltage gated L-type $\mathrm{Ca}^{2+}$ channel provides a trigger to release an increased amount of $\mathrm{Ca}^{2+}$ from the sarcoplasmic reticulum (SR) $\mathrm{Ca}^{2+}$ store through $\mathrm{Ca}^{2+}$-sensitive ryanodine receptors ( $\mathrm{RyRs}$ ). The $\mathrm{Ca}^{2+}$ binds to troponins and initiates contraction before it is taken up by the SR $\mathrm{Ca}^{2+}$ ATPase (SERCA) or transported across the sarcolemma membrane by the sodium calcium exchanger
(NCX) [48]. To further validate the ability of fiber mesh scaffolds to enhance the differentiation of EBs into cardiomyocytes, intracellular $\mathrm{Ca}^{2+}$ transients were recorded from isolated EBs from scaffolds of differing compositions and densities. Because low density fiber scaffolds were shown to enhance $\alpha$-MHC expression more effectively than high fiber density scaffolds, we compared PCL versus 4\%PEG-86\% PGL-10\%CPCL in a low density format and PCL versus glass in a high density format (Figure 5). Due to potential different dye loading conditions of low and high density fiber samples, differences in calcium dynamics between the two types of samples were not directly compared.

The ratio of the fluorescence emission intensities of the Fura-2 fluorophore recorded from EBs at 360 and $380 \mathrm{~nm}$ correlates directly to the absolute intracellular $\mathrm{Ca}^{2+}$ concentration. By recording Fura-2 fluorescence ratios during a train of $1 \mathrm{~Hz}$ field stimulation, the calcium transients corresponding to individual contractions were obtained.

EBs from high fiber density 4\%PEG-86\%PCL-10\%CPCL scaffolds were compared to control (EBs cultured on glass without polymers, Figure $5 \mathrm{a}-\mathrm{c}$ ). Because low fiber density scaffolds were shown to enhance $\alpha$-MHC expression relative to high density scaffolds, the two polymer types were compared in a low fiber density format. For measurements of the intracellular calcium dynamics (Figure $5 \mathrm{~d}-\mathrm{f}$ ), the ratio of the fluorescence intensities of the Fura-2 fluorophore were correlated to intracellular $\mathrm{Ca}^{2+}$. High fiber density 4\%PEG-86\%PCL-10\%CPCL meshes resulted in a larger $\mathrm{Ca}^{2+}$ transient amplitude when compared to control (glass only, Figure 5a, b), and low fiber density 4\%PEG-86\%PCL$10 \%$ CPCL meshes promoted a larger $\mathrm{Ca}^{2+}$ transient amplitude (Figure $5 \mathrm{~d}, \mathrm{e}$ ) and a faster decay time $\tau$, indicative of SERCA activity, when compared to PCL (Figure 5f). Regardless of polymer composition, low fiber density substrates enhanced $\mathrm{Ca}^{2+}$ transient amplitude more effectively than high fiber density 4\%PEG86\% PCL-10\%CPCL, indicating the strong influence of fiber density and mechanical properties on cardiomyogenic differentiation in the presence of Noggin.

For both low and high fiber density substrates, 4\%PEG96\% PCL-10\%CPCL fiber meshes promoted enhanced $\mathrm{Ca}^{2+}$ cycling, which indicates that EBs cultured on this polymer result in more ESC-derived cardiomyocytes compared to PCL only or glass control. These data suggest that the EBs isolated from the terpolymer scaffolds possess a propensity for improved $\mathrm{Ca}^{2+}$ handling, indicating superior cardiac function.

\section{DMH1 Treatment and SERCA2 expression}

We previously showed that dorsomorphin, a small molecule inhibitor of BMP type-I receptor promotes differentiation of murine ESCs into cardiomyocytes by at least 20-fold, at the expense of other mesodermal tissues [28]. Here, we used a more selective BMP inhibitor DMH1 to promote cardiomyogenesis in ES cell. When EBs were differentiated without DMH1, there was minimal induction of cardiomyogenesis [28]. Correspondingly, when ES cells were differentiated in the absence of DMH1 and were stained for SERCA2, there was minimal expression (Figure 6). Thus, although it is possible that increased SECRA2 expression following DMHl treatment is partially from noncardiac sources, our results suggest strongly that increased SERCA2 expression originates from cardiomyocytes induced by DMH1 treatment. Since efficient calcium sequestration into the sarcoplasmic reticulum by SERCA2 is a feature of functional cardiomyocyte (Figure 5f), our data suggests that little or no functional cardiomyocytes form during traditional EB differentiation protocol, although low SERCA2 expression was observed on 4\%PEG-86\%PCL-10\%CPCL (Figure 6). By contrast, EBs in- 
a

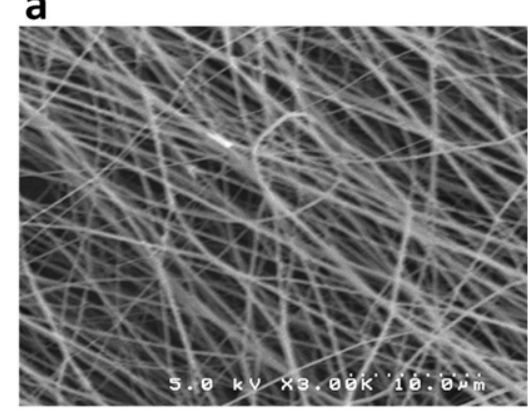

b
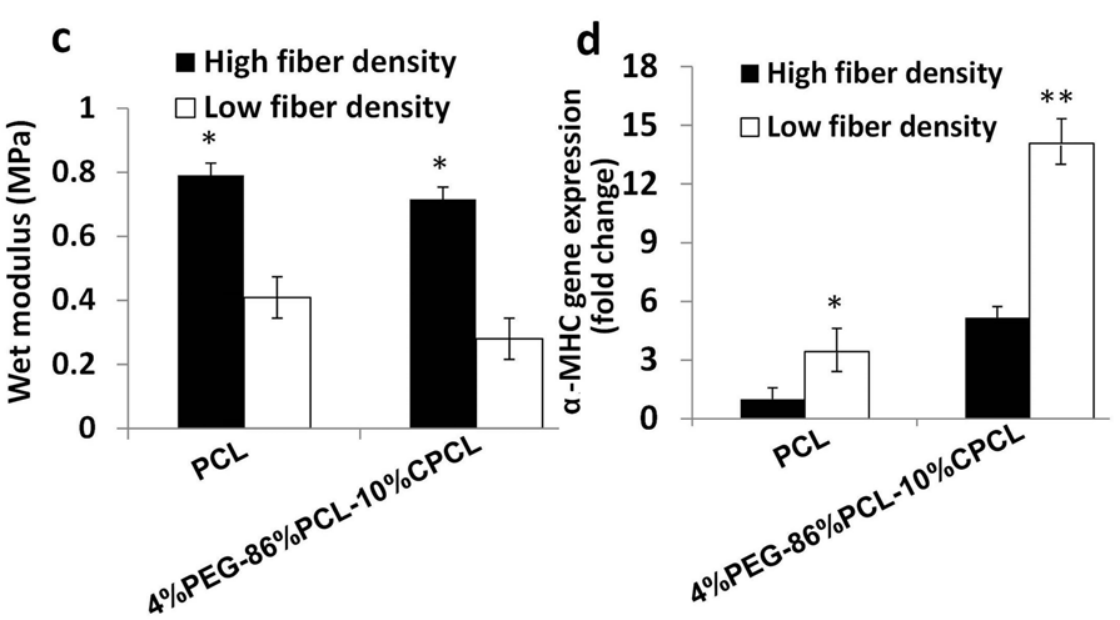

Figure 4. Effect of mechanical properties on EB differentiation. (a) SEM images of (a) high fiber density and (b) low fiber density scaffolds. (c) Wet modulus of PCL and 4\%PEG-86\%PCL-10\%CPCL. * $p<0.05$ versus high density fibers. (d) $\alpha$-MHC gene expression is enhanced on low versus high density fiber scaffolds, indicating improved differentiation. ${ }^{*} p<0.05$ versus high density $\mathrm{PCL}{ }^{*} p<0.0005$ versus high density $4 \% \mathrm{PEG}-86 \% \mathrm{PCL}-$ $10 \%$ CPCL.

doi:10.1371/journal.pone.0028935.g004

duced to cardiomyogenic differentiation by DMH1 demonstrated substantial SERCA2 expression even without polymers (Figure 6). Importantly, while there was no increase in SERCA2 expression on PCL, DMH1- treated EBs grown on low fiber density 4\%PEG86\%PGL-10\%CPCL showed markedly increased SERCA2 expression (Figure 6). These results further support low fiber density $4 \%$ PEG-86\%PCL-10\%CPCL as the preferred substrate for enhanced differentiation of ESCis to mature cardiomyocytes with functional excitation contraction coupling.

\section{Discussion}

ESCs are promising therapeutic candidates in regenerative medicine due to their pluripotency and capacity for self-renewal. In recent years, much progress has been made to understand the microenvironmental cues that control the differentiation of ESCs towards particular lineages [45-48]. Precise guidance of ESC behavior is mandatory for clinical translation of ESC-based therapies to become a reality. Insights into structure-function relationships between the microenvironment and ESCs assist in the design of synthetic scaffolds that more effectively control ESC differentiation. For example, polymeric biomaterials can be designed to mimic a 3D extracellular matrix (ECM) network that facilitates the maintenance of cell homeostasis, phenotype, and behavior [49]. The recapitulation of such cues and signals in a 3D polymer structure is possible by tuning the desired chemical and mechanical properties through copolymerization techniques. The results presented here indicate that polymer scaffold composition and mechanical properties both play central roles in EB formation, development and their subsequent differentiation into cardiomyocytes.

To investigate the influence of scaffold properties on ESC behavior, a library of polymers $(x \%$ PEG- $y \%$ PCL- $z \%$ CPCL $)$ was synthesized, characterized, and prepared as fiber substrates by electrospinning to mimic the ECM network. Each polymeric component was selected for the specific contributions made to the chemical and mechanical properties of the resulting copolymer: PCL is a semi-crystalline, hydrophobic polymer that exhibits slow degradation kinetics with biocompatible byproducts; PEG is a hydrophilic polymer that absorbs water and repels nonspecific protein adsorption through steric exclusion [33]; CPCL further promotes water absorption and facilitates cell attachment by providing a negative charge at the surface. Therefore, the presence of CPCL is expected to buffer the repellent character of PEG while simultaneously increasing hydrophilicity of the resulting material [33]. PCL was selected as the primary component of all polymer types tested because we have previously demonstrated it to be ideal for cardiovascular applications [50,51].

The physical properties of these scaffolds were first evaluated for their applicability for cardiac regeneration. The modulus of native rat myocardium ranges from about 10 to $150 \mathrm{kPa}[31,52,53]$. The differentiation of cardiomyocytes from cardiac stem cells on a square grid poly $L$-(lactic acid) scaffold with a Young's modulus of about $300 \mathrm{kPa}$ was successfully demonstrated [54]. Because the wet moduli of all scaffolds fell within the same order of magnitude, the electrospun test polymers were predicted to be ideal for this 


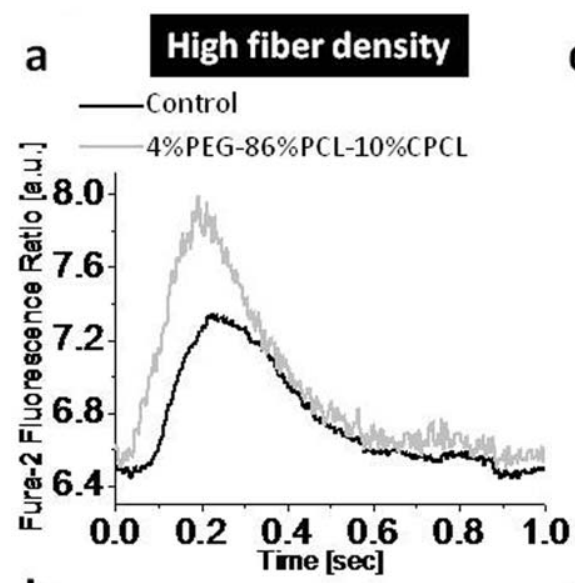

d Low fiber density
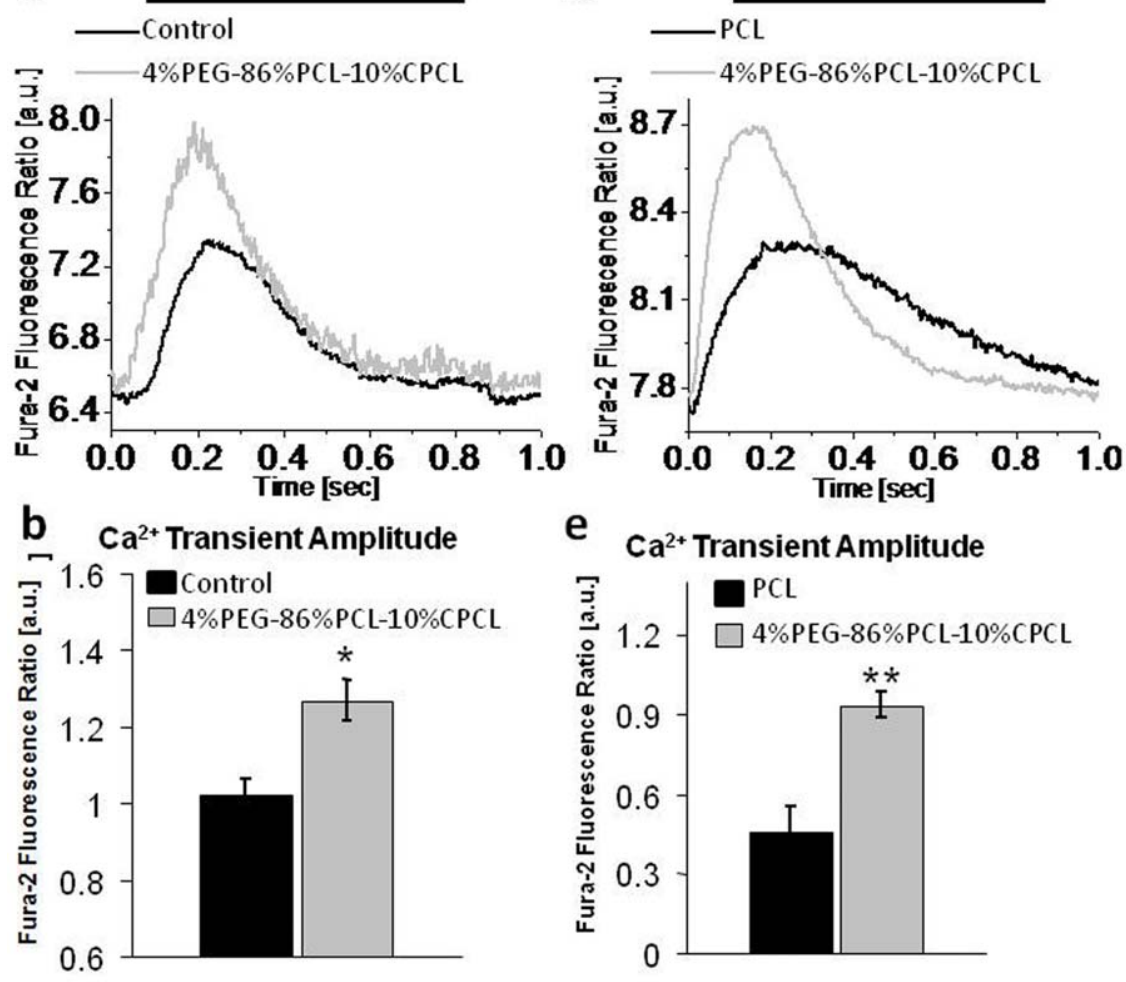

e $\mathrm{Ca}^{2+}$ Transient Amplitude
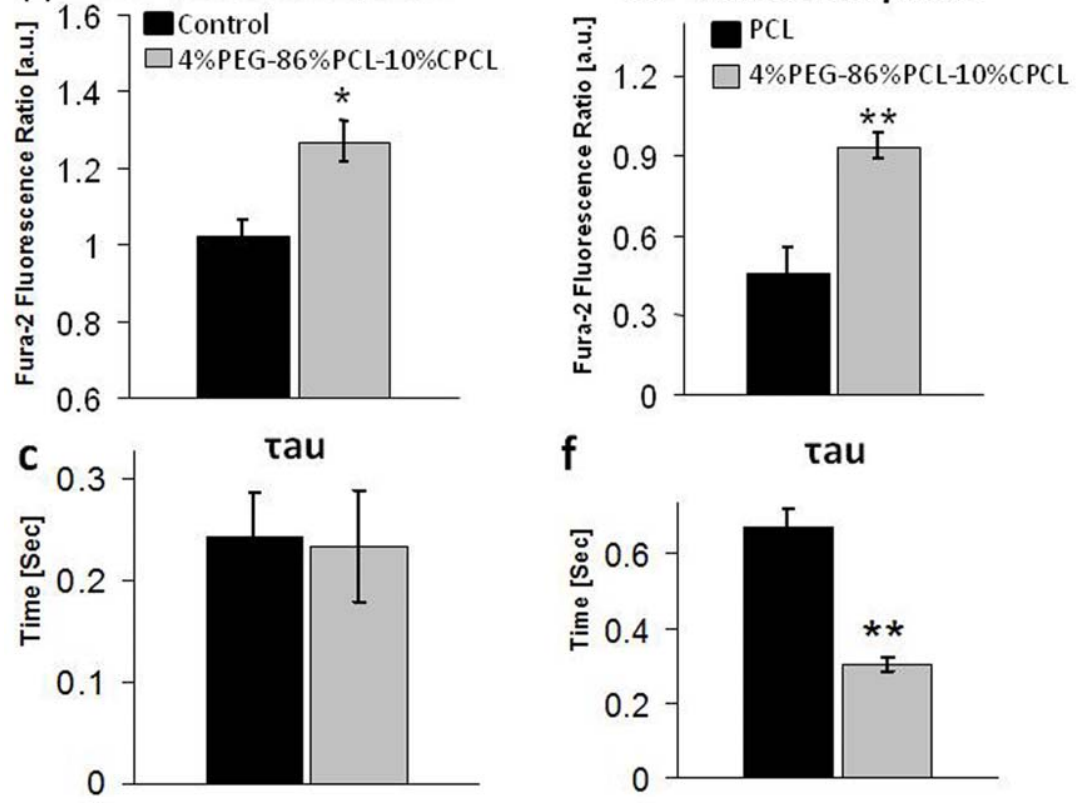

Figure 5. Polymer substrate elasticity affects $\mathrm{Ca}^{2+}$ dynamics of EBs. $\mathrm{Ca}^{2+}$ transients were recorded from isolated EBs from polymer scaffolds using the fluorescent ratiometric calcium dye Fura-2. EBs were subjected to $1 \mathrm{~Hz}$ field-stimulations during recordings. (a, d) Representative fluorescence traces showing the calcium transient accompanying a electrically stimulated single contraction. (b, e) $\mathrm{Ca}^{2+}$ transient amplitude, measured as the difference between diastolic and systolic Ca fluorescence intensities. (c, f) Decay constant of the $\mathrm{Ca}^{2+}$ transient, calculated by fitting the decay to a single exponential decay function. ${ }^{*} p<0.05$ and ${ }^{* *} p<0.0005$. doi:10.1371/journal.pone.0028935.g005

application. We therefore conducted a series of in vitro tests to evaluate enhancement of ESC cardiomyogenic differentiation on polymer substrates. Eventually, 4\%PEG-86\%PCL-10\% CPCL was selected as an ideal chemical composition among the test polymers. Moreover, the wet modulus of 4\%PEG-86\%PCL$10 \%$ CPCL low density fibers showed a modulus around $280 \mathrm{kPa}$, which is similar to myocardium modulus, and our results demonstrated the promoted differentiation of cardiomyocytes from mouse ESCs on this type of fibers.

Copolymerization techniques enabled us to evaluate the effects of scaffold composition and the resulting mechanical properties on ESC differentiation. Compared to EBs grown on control glass slides, EBs grown on all test scaffolds exhibited enhanced adherence and viability, elevated intracellular $\mathrm{H}_{2} \mathrm{O}_{2}$ production, and increased $\alpha$-MHC expression at the gene and protein levelsall of which indicate differentiation towards a cardiomyogenic lineage [45-47]. The slight elevation in intracellular $\mathrm{H}_{2} \mathrm{O}_{2}$ in EBs cultured on 4\%PEG-86\%PCL-10\%CPCL represents healthy redox signaling that promotes differentiation without excessive, pathogenic overproduction of ROS [47]. While other polymers also caused an increase in intracellular $\mathrm{H}_{2} \mathrm{O}_{2}$ without a loss of cell viability (Figures 2), only the 4\%PEG-86\%PCL-10\%CPCL terpolymer was able to promote a concurrent up-regulation of $\alpha$-MHC gene and protein expression. Based on these data, we selected this particular polymer composition as the optimal formulation for enhancing EB differentiation for the remainder of the studies. In contrast, PCL fiber meshes demonstrated the weakest ability (closest to control) to enhance intracellular $\mathrm{H}_{2} \mathrm{O}_{2}$ production and $\alpha$-MHC expression relative to other test polymer types; therefore, PCL was selected as the most suitable polymer control for the remainder of experiments.

Because substrate elasticity has been shown to tightly regulate stem cell differentiation, we evaluated the effects of scaffold mechanical properties on cardiomyogenic differentiation $[55,56]$. 


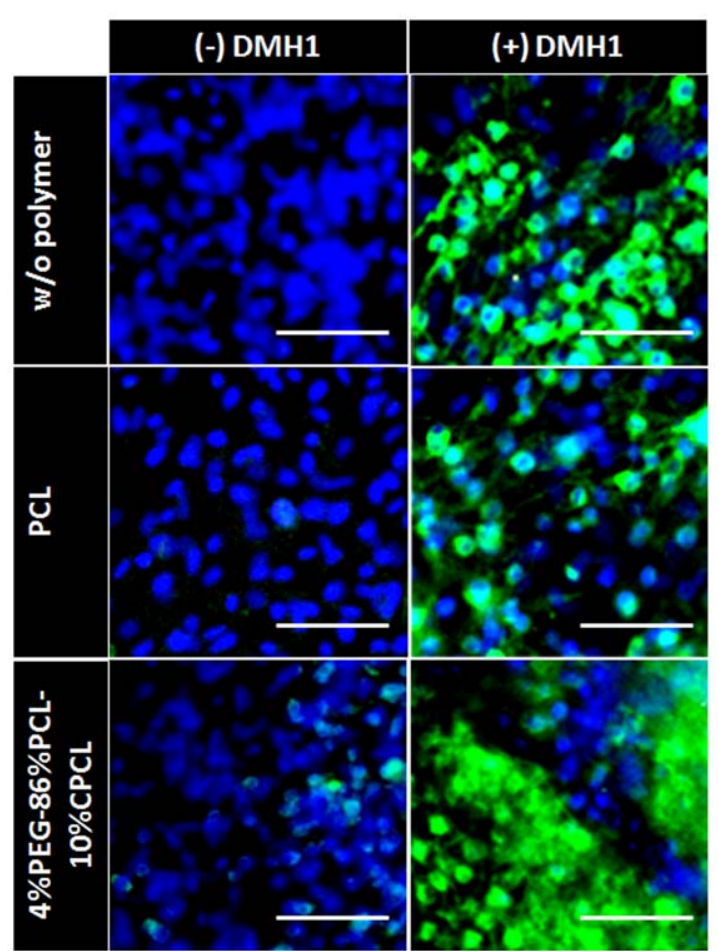

Figure 6. EB differentiation on polymer fiber scaffolds in the presence of DMH1. EBs with and without DMH1 treatment were stained for SERCA2a, an indicator of active $\mathrm{Ca}^{2+}$ transient. EBs on 4\%PEG-86\%PCL-10\%CPCL exhibited enhanced expression of SERCA2a, compared to untreated EBs on PCL scaffolds or glass alone. Scale bars $=50 \mu \mathrm{m}$.

doi:10.1371/journal.pone.0028935.g006

To tune the scaffold mechanical properties, fiber scaffolds were deposited at high and low fiber densities by altering electrospinning parameters. The diameter, morphology and alignment of both fiber scaffold types were kept constant by applying similar electrospinning conditions. Compared to high fiber density scaffolds, EBs cultured on low fiber density 4\%PEG-86\%PCL$10 \%$ CPCL scaffolds exhibited enhanced $\alpha$-MHC gene expression, indicating that a compliant substrate of the same chemical composition more effectively enhances cardiac differentiation in the presence of Noggin. We then hypothesized that this same scaffold would promote the most functional ESC-derived cardiomyocytes that exhibit calcium signaling dynamics that are characteristic of ventricular excitation contraction coupling. Indeed, this was verified by measurements of $\mathrm{Ca}^{2+}$ transients which revealed a physiological time course for the de- and repolarization and functional cardiac excitation contraction coupling.

These findings were further supported by monitoring the expression of SERCA2a, a protein involved in $\mathrm{Ca}^{2+}$ transport. In the absence of DMH1, an inhibitor of the BMP signaling pathway, only EBs cultured on low fiber density 4\%PEG-86\%PCL$10 \%$ CPCL scaffolds exhibited a recognizable level of SERCA2a expression (Figure 6). Upon treatment with DMH1, EBs on all substrates expressed SERCA2a, but those cultured on 4\%PEG$86 \%$ PCL-10\%CPCL demonstrated the most significant upregulation (Figure 6). These data indicate that low fiber density 4\%PEG-86\%PCL-10\%CPCL scaffolds optimally enhanced the physiologically-relevant cardiomyogenic differentiation of ESCs.
Matrix stiffness directs stem cell differentiation into particular lineages on substrates with elasticity similar to respective native tissue [56]. In our study, the wet modulus of 4\%PEG-86\%PCL90\% CPCL low density fibers was about $280 \mathrm{kPa}$, which was relatively close to the modulus of the native myocardium $[31,52,53]$ and induced the highest cardiomyocyte differentiation compared to stiffer substrates (Figure 3,4 and 6). Stem cells sense the rigidity of substrate and are expected to have elevated levels of phosphorylated focal-adhesion kinases when cultured on stiffer scaffolds [56,57], which in turn promote the proliferation or migration of stem cells and inhibit the cardiomyocyte differentiation [58]. Moreover, the introduction of high porosity by low density fibers not only decreased the elasticity, but also contributed more accessible surface area to cells [59]. Thus the 4\%PEG-PCLCPCL low density fibers led to enhanced cardiogenesis as a result of combined low elasticity and high porosity.

Our findings demonstrate that the augmented differentiation of ESCs into healthy and electrophysiologically-functional cardiomyocytes relies heavily upon scaffold composition and mechanical properties. Through scaffold preparation by electrospinning, we have identified low fiber density 4\%PEG-86\%PCL-10\%CPCL as the best substrate for enhanced cardiomyogenic differentiation of ESCs in the presence of the BMP inhibitor Noggin or DMH1. We have deduced that a more compliant substrate effectively promotes $\mathrm{EB}$ adhesion and cardiomyogenic differentiation, as verified by changes in gene and protein expression, biochemical activities, and $\mathrm{Ca}^{2+}$ signaling dynamics.

This approach for cardiac tissue engineering further supports the development of material-based guidance of ESC differentiation through elucidation of cell-matrix interactions. Our findings provide additional insight into the development of instructive matrices for enhanced post-operative differentiation, an understanding that is essential for the clinical translation of ESCs for cardiac repair. The advantages of our approach include scalability, reproducibility, low cost, and simplicity of fabrication. Additionally, the electrophysiological behavior of differentiated cardiomyocytes using this approach was similar to those described by others using alternative methods, thereby further supporting the utility of this approach as a feasible, clinically-relevant method for directed ESC differentiation.

\section{Conclusions}

The present study describes the synthesis and characterization of electrospun fibers comprised of a subset of a library of polymers with different physicochemical properties. Among the polymers tested, the polymer composition of 4\%PEG-86\%PCL-10\%CPCL optimally facilitated the differentiation of ESCs into functional cardiomyocytes. This effect correlated with the local density of deposited fibers, demonstrating a relationship between substrate mechanical properties and cell differentiation. The resulting cardiomyocytes were electrophysiologically functional, possessing desired $\mathrm{Ca}^{2+}$ depolarization and repolarization pathways. These results are promising for the treatment of cardiac ischemia, where the ensuing myocardial hypoxia, necrosis, and fibrosis may be treated through the delivery of a tissue-engineered myocardial patch. The methods described provide an efficient way to induce functional cardiomyocytes from pure ESCs, which is of great interest to the areas of regenerative medicine biomaterials, tissue engineering, cardiology, and stem cell biology.

\section{Acknowledgments}

The authors thank Dr. Sabine Huke at Vanderbilt University Medical Center for providing SERCA2a IgG antibodies. 


\section{Author Contributions}

Conceived and designed the experiments: MKG JMW RV SWC DKJ SSY TKF XW TDG CCH FJB AKH H-JS. Performed the experiments: MKG JMW RV SWC DKJ SSY TKF. Analyzed the data: MKG RV SWC DKJ

\section{References}

1. Taylor DA (2004) Cell-based myocardial repair: how should we proceed? Int J Cardiol 95 Suppl 1: S8-12.

2. Wang F, Guan J (2010) Cellular cardiomyoplasty and cardiac tissue engineering for myocardial therapy. Adv Drug Deliv Rev 62: 784-797.

3. Li RK, Mickle DA, Weisel RD, Zhang J, Mohabeer MK (1996) In vivo survival and function of transplanted rat cardiomyocytes. Circ Res 78: 283-288.

4. Delcarpio JB, Claycomb WC (1995) Cardiomyocyte transfer into the mammalian heart. Cell-to-cell interactions in vivo and in vitro. Ann N Y Acad Sci 752: 267-285.

5. Reinecke H, Murry CE (2000) Transmural replacement of myocardium after skeletal myoblast grafting into the heart. Too much of a good thing? Cardiovasc Pathol 9: 337-344

6. Orlic D, Kajstura J, Chimenti S, Jakoniuk I, Anderson SM, et al. (2001) Bone marrow cells regenerate infarcted myocardium. Nature 410: 701-705.

7. Murry CE, Soonpaa MH, Reinecke H, Nakajima H, Nakajima HO, et al. (2004) Haematopoietic stem cells do not transdifferentiate into cardiac myocytes in myocardial infarcts. Nature 428: 664-668.

8. Toma C, Pittenger MF, Cahill KS, Byrne BJ, Kessler PD (2002) Human mesenchymal stem cells differentiate to a cardiomyocyte phenotype in the adult murine heart. Circulation 105: 93-98.

9. Mangi AA, Noiseux N, Kong D, He H, Rezvani M, et al. (2003) Mesenchymal stem cells modified with Akt prevent remodeling and restore performance of infarcted hearts. Nat Med 9: 1195-1201.

10. Oh H, Bradfute SB, Gallardo TD, Nakamura T, Gaussin V, et al. (2003) Cardiac progenitor cells from adult myocardium: homing, differentiation, and fusion after infarction. Proc Natl Acad Sci U S A 100: 12313-12318.

11. Beltrami AP, Barlucchi L, Torella D, Baker M, Limana F, et al. (2003) Adult cardiac stem cells are multipotent and support myocardial regeneration. Cell 114: 763-776.

12. Min JY, Yang Y, Converso KL, Liu L, Huang Q et al. (2002) Transplantation of embryonic stem cells improves cardiac function in postinfarcted rats. J Appl Physiol 92: 288-296.

13. Mummery C, Ward-van Oostwaard D, Doevendans P, Spijker R, van den Brink S, et al. (2003) Differentiation of human embryonic stem cells to cardiomyocytes: role of coculture with visceral endoderm-like cells. Circulation 107: 2733-2740.

14. Xu C, Police S, Rao N, Carpenter MK (2002) Characterization and enrichment of cardiomyocytes derived from human embryonic stem cells. Circ Res 91: 501-508.

15. Klug MG, Soonpaa MH, Koh GY, Field LJ (1996) Genetically selected cardiomyocytes from differentiating embronic stem cells form stable intracardiac grafts. J Clin Invest 98: 216-224.

16. Behfar A, Zingman LV, Hodgson DM, Rauzier JM, Kane GC, et al. (2002) Stem cell differentiation requires a paracrine pathway in the heart. FASEB J 16: 1558-1566.

17. Kehat I, Kenyagin-Karsenti D, Snir M, Segev H, Amit M, et al. (2001) Human embryonic stem cells can differentiate into myocytes with structural and functional properties of cardiomyocytes. J Clin Invest 108: 407-414.

18. Etzion S, Battler A, Barbash IM, Cagnano E, Zarin P, et al. (2001) Influence of embryonic cardiomyocyte transplantation on the progression of heart failure in a rat model of extensive myocardial infarction. J Mol Cell Cardiol 33: 1321-1330.

19. Leor J, Aboulafia-Etzion S, Dar A, Shapiro L, Barbash IM, et al. (2000) Bioengineered cardiac grafts: A new approach to repair the infarcted myocardium? Circulation 102: III56-61.

20. Muller-Ehmsen J, Whittaker P, Kloner RA, Dow JS, Sakoda T, et al. (2002) Survival and development of neonatal rat cardiomyocytes transplanted into adult myocardium. J Mol Cell Cardiol 34: 107-116.

21. Zhang M, Methot D, Poppa V, Fujio Y, Walsh K, et al. (2001) Cardiomyocyte grafting for cardiac repair: graft cell death and anti-death strategies. J Mol Cell Cardiol 33: 907-921.

22. Reinecke H, Murry CE (2002) Taking the death toll after cardiomyocyte grafting: a reminder of the importance of quantitative biology. J Mol Cell Cardiol 34: 251-253.

23. Kellar RS, Landeen LK, Shepherd BR, Naughton GK, Ratcliffe A, et al. (2001) Scaffold-based three-dimensional human fibroblast culture provides a structural matrix that supports angiogenesis in infarcted heart tissue. Circulation 104: 2063-2068.

24. Langer R, Tirrell DA (2004) Designing materials for biology and medicine. Nature 428: 487-492.

25. Gu QA, Kong Y, Schneede J, Xiao YB, Chen L, et al. (2010) VKORC11639G >A, CYP2C9, EPHX1691A > G genotype, body weight, and age are important predictors for warfarin maintenance doses in patients with mechanical heart valve prostheses in southwest China. Eur J Clin Pharmacol 66: 1217-1227.

26. Alper J (2009) Geron gets green light for human trial of ES cell-derived product. Nat Biotechnol 27: 213-214.
CCH XW FJB AKH H-JS. Contributed reagents/materials/analysis tools: MKG JMW RV SWC DKJ SSY TKF XW TDG CCH FJB AKH H-JS. Wrote the paper: MKG RV SWG XW CGH FJB H-JS.

27. Strauss S (2010) Geron trial resumes, but standards for stem cell trials remain elusive. Nat Biotechnol 28: 989-990.

28. Hao J, Daleo MA, Murphy CK, et al. (2008) Dorsomorphin, a selective small molecule inhibitor of BMP signaling, promotes cardiomyogenesis in embryonic stem cell. PLoS ONE 3: e2904.

29. Leor J, Amsalem Y, Cohen S (2005) Cells, scaffolds, and molecules for myocardial tissue engineering. Pharmacol Ther 105: 151-163.

30. Alperin C, Zandstra PW, Woodhouse KA (2005) Polyurethane films seeded with embryonic stem cell-derived cardiomyocytes for use in cardiac tissue engineering applications. Biomaterials 26: 7377-7386.

31. Jawad H, Lyon AR, Harding SE, Ali NN, Boccaccini AR (2008) Myocardial tissue engineering. Br Med Bull 87: 31-47.

32. Sinha VR, Bansal K, Kaushik R, Kumria R, Trehan A (2004) Poly-epsiloncaprolactone microspheres and nanospheres: an overview. Int J Pharm 278: $1-23$.

33. Sung HJ, Luk A, Murthy NS, Liu E, Jois M, et al. (2010) Poly(ethylene glycol) as a sensitive regulator of cell survival fate on polymeric biomaterials: the interplay of cell adhesion and pro-oxidant signaling mechanisms. Soft Matter 6: 5196-5205.

34. Hammon M, Herrmann M, Bleiziffer O, Pryymachuk G, Andreoli L, et al. (2011) Role of guanylate binding protein-1 in vascular defects associated with chronic inflammatory diseases. J Cell Mol Med 15: 1582-1592.

35. Ou DB, He Y, Chen R, Teng JW, Wang HT, et al. (2011) Three-dimensional co-culture facilitates the differentiation of embryonic stem cells into mature cardiomyocytes. J Cell Biochem.

36. Lu WN, Lu SH, Wang HB, Li DX, Duan CM, et al. (2009) Functional improvement of infarcted heart by co-injection of embryonic stem cells with temperature-responsive chitosan hydrogel. Tissue Eng Part A 15: 1437-1447.

37. Gimenez S, Ponsart S, Coudane J, Vert M (2001) Synthesis, properties and in vitro degradation of carboxyl-bearing PCL. J Bioact Compat Polym 16: 32-46.

38. Sung HJ, Chandra P, Treiser MD, Liu E, Iovine CP, et al. (2009) Synthetic polymeric substrates as potent pro-oxidant versus anti-oxidant regulators of cytoskeletal remodeling and cell apoptosis. J Cell Physiol 218: 549-557.

39. Chandra P, Lai K, Sung HJ, Murthy NS, Kohn J (2010) UV laser-ablated surface textures as potential regulator of cellular response. Biointerphases 5 : 53-59.

40. Palermo J, Gulick J, Colbert M, Fewell J, Robbins J (1996) Transgenic Remodeling of the Contractile Apparatus in the Mammalian Heart. Circ Res 78: 504-509.

41. Krause C, Guzman A, Knaus P Noggin. Int J Biochem Cell Biol 43: 478-481.

42. Sung HJ, Yee A, Eskin SG, McIntire LV (2007) Cyclic strain and motion control produce opposite oxidative responses in two human endothelial cell types. Am J Physiol Cell Physiol 293: C87-94.

43. Wang YC, Li Y, Yang XZ, Yuan YY, Yan LF, et al. (2009) Tunable Thermosensitivity of Biodegradable Polymer Micelles of Poly (epsilon-caprolactone) and Polyphosphoester Block Copolymers. Macromolecules 42: 3026-3032.

44. Greiner A, Wendorff JH (2007) Electrospinning: A fascinating method for the preparation of ultrathin fibres. Angew Chem Int Ed Engl 46: 5670-5703.

45. Crespo FL, Sobrado VR, Gomez L, Cervera AM, McCreath KJ Mitochondria reactive oxygen species mediate cardiomyocyte formation from embryonic stem cells in high glucose. Stem Cells 28: 1132-1142.

46. Ding L, Liang XG, Hu Y, Zhu DY, Lou YJ (2008) Involvement of p38MAPK and reactive oxygen species in icariin-induced cardiomyocyte differentiation of murine embryonic stem cells in vitro. Stem Cells Dev 17: 751-760.

47. Sauer H, Wartenberg M (2005) Reactive oxygen species as signaling molecules in cardiovascular differentiation of embryonic stem cells and tumor-induced angiogenesis. Antioxid Redox Signal 7: 1423-1434.

48. Bers DM (2002) Cardiac excitation-contraction coupling. Nature 415: 198-205.

49. Hubbell JA (2003) Materials as morphogenetic guides in tissue engineering. Curr Opin Biotech 14: 551-558.

50. Sung HJ, Su J, Berglund JD, Russ BV, Meredith JC, et al. (2005) The use of temperature-composition combinatorial libraries to study the effects of biodegradable polymer blend surfaces on vascular cells. Biomaterials 26: 4557-4567.

51. Sung HJ, Meredith G, Johnson C, Galis ZS (2004) The effect of scaffold degradation rate on three-dimensional cell growth and angiogenesis. Biomaterials 25: 5735-5742.

52. Engelmayr GC, Jr., Cheng M, Bettinger CJ, Borenstein JT, Langer R, et al. (2008) Accordion-like honeycombs for tissue engineering of cardiac anisotropy. Nat Mat 7: 1003-1010.

53. Bhana B, Iyer RK, Chen WL, Zhao R, Sider KL, et al. (2010) Influence of substrate stiffness on the phenotype of heart cells. Biotech Bioeng 105: 1148-1160. 
54. Forte G, Carotenuto F, Pagliari F, Pagliari S, Cossa P, et al. (2008) Criticality of the biological and physical stimuli array inducing resident cardiac stem cell determination. Stem Cells 26: 2093-2103.

55. Li R, Siu DC (2008) Directed Differentiation and Maturation of Stem CellDerived Cardiomyocytes. In: Organization WIP, ed. World International Patent Organization, C12N 5/00 (2006.01), C12N 15/00 (2006.01) ed. United Nations.

56. Engler AJ, Sen S, Sweeney HL, Discher DE (2006) Matrix elasticity directs stem cell lineage specification. Cell 126: 677-689.
57. Schwartz MA, Ginsberg MH (2002) Networks and crosstalk: integrin signalling spreads. Nat Cell Biol 4: E65-E68.

58. Hakuno D, Takahashi T, Lammerding J, Lee RT (2005) Focal adhesion kinase signaling regulates cardiogenesis of embryonic stem cells. J Biol Chem 280: 39534-39544.

59. Ou DB, He Y, Chen R, Teng JW, et al. (2011) Three-dimensional co-culture facilitates the differentiation of embryonic stem cells into mature cardiomyocytes. J Cell Biochem 112: 3555-3562. 